University of Nebraska - Lincoln

DigitalCommons@University of Nebraska - Lincoln

USDA National Wildlife Research Center - Staff

Publications

U.S. Department of Agriculture: Animal and Plant Health Inspection Service

\title{
$8-2012$
}

\section{Management of Invasive Coqui Frog Populations in Hawaii}

William C. Pitt

National Wildlife Research Center, will.pitt@aphis.usda.gov

Karen H. Beard

Utah State University, karen.beard@usu.edu

Rogelio E. Doratt

Colorado State University, redoratt@rams.colostate.edu

Follow this and additional works at: https://digitalcommons.unl.edu/icwdm_usdanwrc

Pitt, William C.; Beard, Karen H.; and Doratt, Rogelio E., "Management of Invasive Coqui Frog Populations in Hawaii" (2012). USDA National Wildlife Research Center - Staff Publications. 1181.

https://digitalcommons.unl.edu/icwdm_usdanwrc/1181

This Article is brought to you for free and open access by the U.S. Department of Agriculture: Animal and Plant Health Inspection Service at DigitalCommons@University of Nebraska - Lincoln. It has been accepted for inclusion in USDA National Wildlife Research Center - Staff Publications by an authorized administrator of DigitalCommons@University of Nebraska - Lincoln. 


\title{
MANAGEMENT OF INVASIVE COQUI FROG POPULATIONS IN HAWAII
}

\author{
William C. Pitt, USDA/APHIS/WS/ National Wildlife Research Center, Hilo Field Station, Hilo, USA. \\ Corresponding author. Email: will.pitt@aphis.usda.gov; Karen H. Beard, Department of Wildland Resources and \\ the Ecology Center, Utah State University, Logan, UT 84322-5230, USA; Rogelio E. Doratt*, USDA/APHIS/WS/ \\ National Wildlife Research Center, Hilo Field Station, Hilo, USA, *Current Address: Colorado State University, \\ Center for Environmental Management of Military Lands, Pohakuloa Training Area, Hilo, Hawaii 96720
}

Keywords: Coqui, Hawaii, frog, invasive species, management

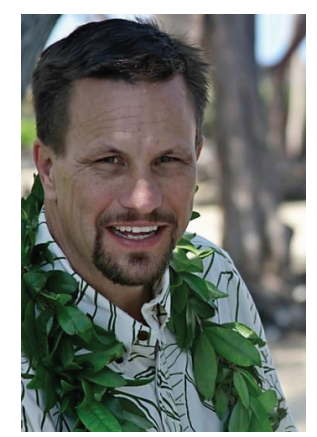

William Pitt

During the last 25 years, two species of Eleutherodactylus frogs, coqui and greenhouse frogs, have become established in Hawaii and other Pacific Islands. Coqui frogs, Eleutherodactylus coqui, were introduced to Hawaii prior to 1988 via the horticultural trade (Kraus \& Campbell 2002). Since their introduction, the number and size of coqui frog infestations have rapidly increased and frogs have spread throughout the four main Hawaiian Islands with the largest infestation on the island of Hawaii. Coqui frogs are small ( $<65 \mathrm{~mm}$ in length) nocturnal tree frogs that are endemic to the island Puerto Rico (Beard et al. 2008). They are completely terrestrial and do not need open water for development because the frogs develop directly from eggs into small froglets. The most distinctive feature of coqui frogs are their loud two-note mating call, "ko-kee" and the call from a single male may exceed $85 \mathrm{db}$ at $0.5 \mathrm{~m}$ (Beard \& Pitt 2005). In Hawaii, coqui frogs have few predators, few competitors, abundant food resources and ideal climatic conditions. Populations of frogs are abundant in Hawaii with population densities exceeding 90,000 frogs per ha (Beard et al. 2008).

As a result of the extremely dense frog populations and the loud mating call, coqui frogs have affected Hawaii's environment, economy, and human health. In areas with high frog densities, frogs may consume 690,000 invertebrates/ha/night, reduce invertebrate diversity, and may impact native invertebrate species (Beard 2007; Choi \& Beard 2012). Indirectly, the large coqui populations may also alter nutrient cycling and plant herbivory, which could affect the native plants and the invasion of non-native plants (Sin et al. 2008). Coqui frogs may also compete with native species, provide food for invasive predators, or facilitate the establishment of other invasive species, such as the brown tree snake (Boiga irregularis). Due to the loud mating calls and dense populations, many people do not wish to reside in areas with coqui frogs because they disturb their sleep and night time tranquillity. This noise disturbance has led to decreases in property values of land occupied by coqui frogs (Kaiser \& Burnett 2006). Moreover, the reluctance of people to risk purchasing products infested with frogs or frog eggs has led to many impacts on the floriculture industry. Plant growers have experienced decreased sales, increased quarantine procedures, destruction of plant shipments, and increased pest control costs (see Beard et al. 2009 for a review). These increased costs have forced several plant producers to move or go out of business.

\section{Management options}

For the last 15 years, many options to control frogs have been considered, but few have been proven effective and safe. Prior to this time, very little research had been conducted on managing invasive frogs anywhere in the world. The problem with developing a control method for frog populations was the method needed to be effective against individual frogs, would be applied over large areas, be effective in a variety of environments, be safe for non-target plants and animals, and be safe and effective to implement by the general public. After

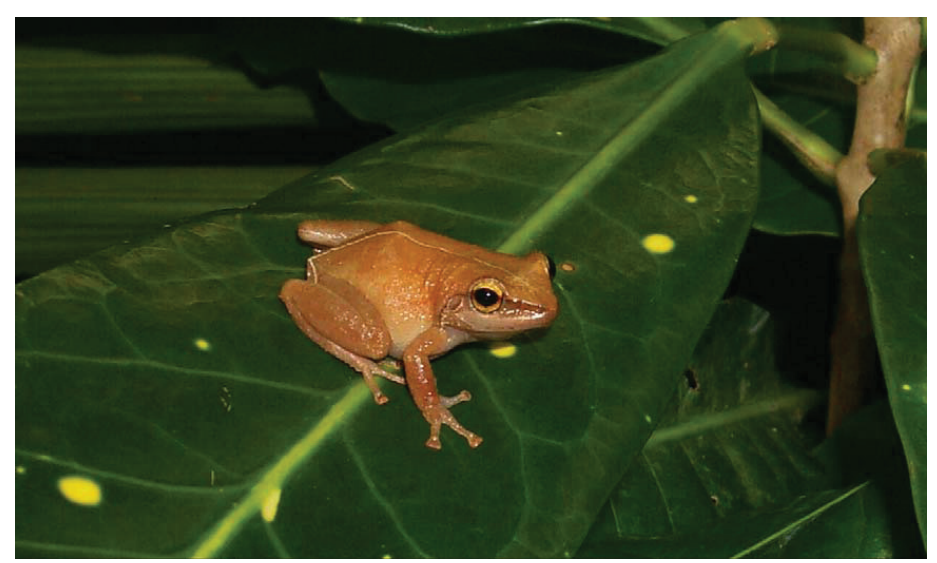

Figure I. A typical coqui frog on a Codiaeum variegatum leaf (USDA APHIS Wildlife Services' National Wildlife Research Center). 


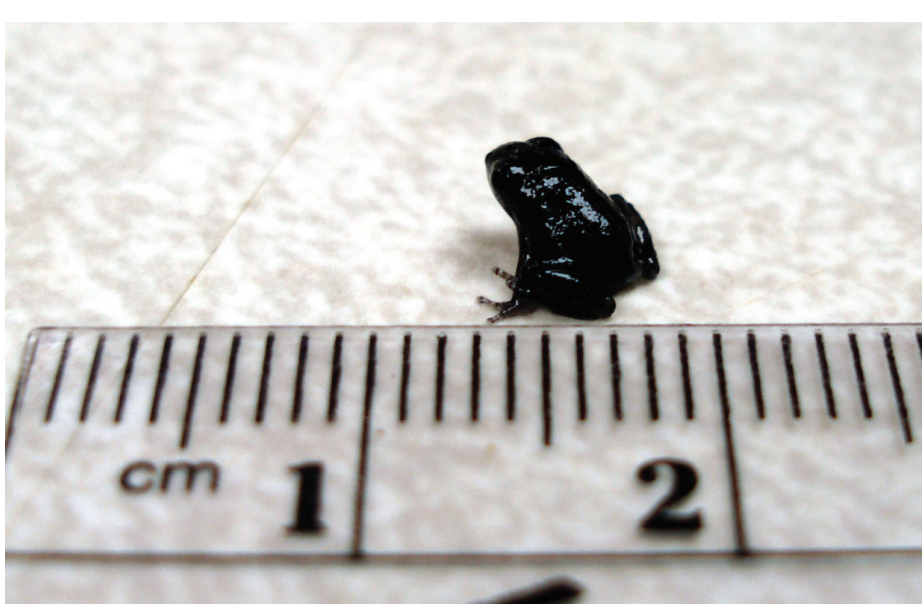

Figure 2. One day old coqui frog with a ruler for size reference (USDA APHIS Wildlife Services' National Wildlife Research Center).

years of research, few control options (mechanical, biological, and chemical) remained for management of frog populations, but some methods were effective under limited circumstances.

\section{Mechanical methods}

Many mechanical methods have been evaluated for controlling coqui frogs including traps, barriers, steam treatments, vegetation management, and hand capture. Several traps were developed that took advantage of the frogs need for daytime retreats, male calling sites, and foraging efforts. Although the traps were effective in capturing some frogs, they were not effective at controlling large populations (Sugihara 2000). Barriers were developed that consisted of tightly woven fabric that prevented frogs from climbing onto the material and were high enough that the frogs could not jump over the barriers. The barriers prevented frogs from moving into smaller areas, such as plant production facilities. Steam or hot water baths are effective in treating plant shipments to control a variety of pests. Frogs and frog eggs are killed when exposed to hot water applied at $45^{\circ} \mathrm{C}$ for three minutes or when exposed to steam applied at $45{ }^{\circ} \mathrm{C}, 90 \%$ humidity (Hara et al. 2010). This technique is effective for plant shipments, but may affect some sensitive plants. Removing or altering vegetation has been effective at reducing the density of frogs in certain areas. However, apart from removing all vegetation, frogs still persist in areas with less attractive landscaping. Hand capturing frogs is an effective way to remove a few individuals from specific locations. Typically, adult males are primarily captured because they can be located when calling, thus even intensive hand capture operations are unlikely to reduce populations over large areas.

\section{Biological control}

Biological control or the release of organisms (disease, parasite, or predator) likely to combat the frog was initially considered because Hawaii has no native frog populations. Unfortunately, no diseases or organisms have been identified that would effectively reduce coqui frog populations and release of non-native organism may have unintended conse- quences. One disease organism that has been implicated in frog population declines worldwide, the chytrid fungus (Batrachochytrium dendrobatidis), is already established in coqui frog populations in Hawaii and coqui frogs are relatively resistant to the disease (Beard \& O’Neill 2005). Frog parasites were also evaluated for their potential as biocontrol agents. Only one parasite was identified from Puerto Rico that could have an effect on coqui frogs, but the parasite did not affect coqui growth or survivorship (Marr et al. 2008). The release of a coqui predator has low potential for success in controlling widespread frog populations. The high density of coqui frogs in Puerto Rico reveals that coqui frogs would be very abundant even with many predators, competitors, and parasites. In Hawaii, many abundant predators eat coqui frogs (mongoose, rats, chickens), but frogs do not constitute a major portion of their diet and these predators probably have little effect on coqui populations (Beard \& Pitt 2006).

Biological control can also have unintended consequences that affect other organisms or the environment. If a disease were found that significantly affected coqui frogs, there is a chance that a frog infected with a disease could be transported to other states or countries. Thus, releasing a disease organism may affect frog populations elsewhere and could restrict trade. An effective frog predator, could also switch to eating native species, such as birds, if it greatly reduced frog populations.

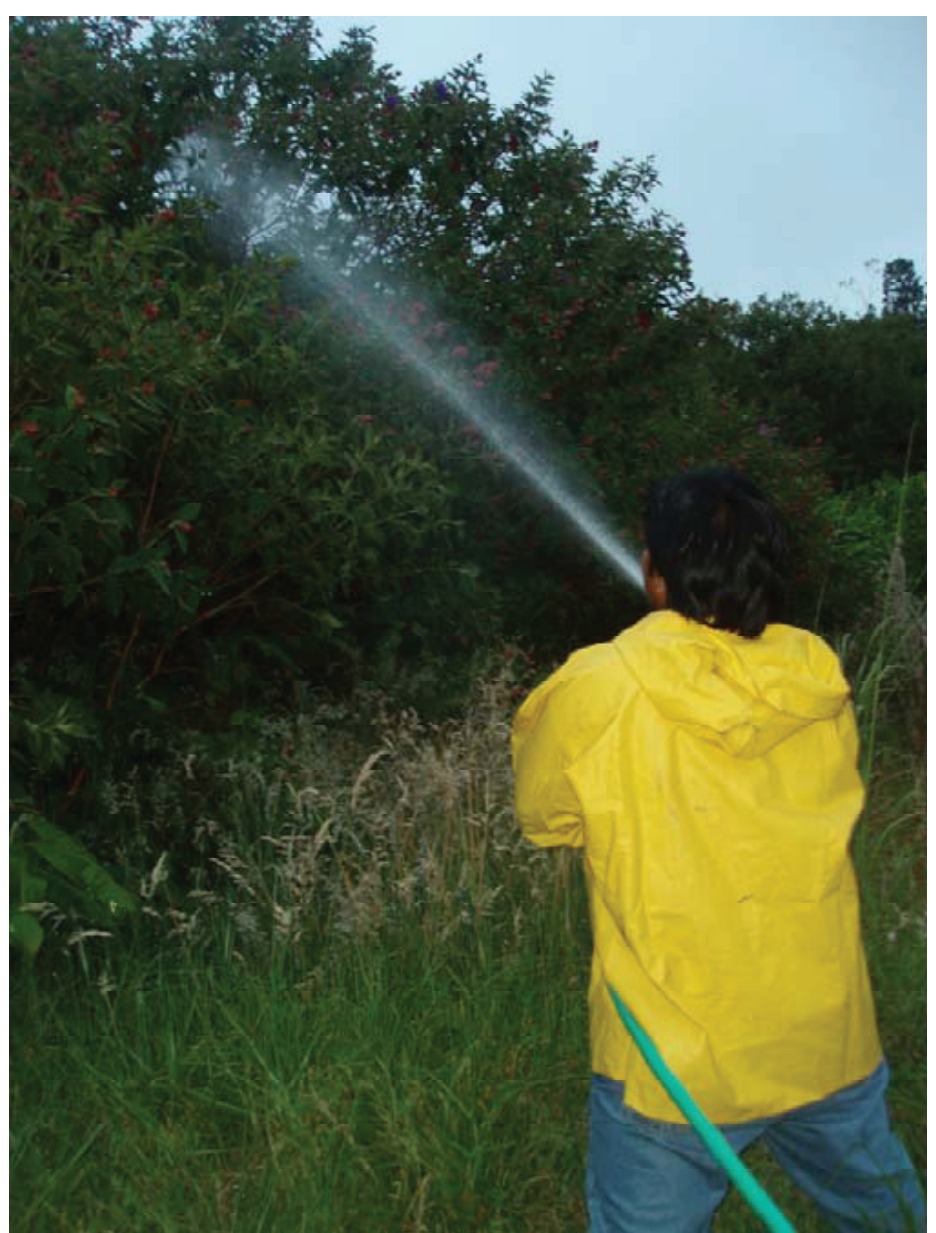

Figure 3. Hand spraying a $16 \%$ citric acid solution to target coqui frogs in vegetation. The hose is connected to a 400 gallon mobile tank system (USDA APHISWildlife Services' National Wildlife Research Center). 


\section{Chemical control}

Chemical control has been the most effective method to control frog populations across the Hawaiian Islands. The key to effective chemical control is developing a method that is effective and safe for use in a variety of habitats. Since 1998, US Department of Agriculture (USDA) conducted multiple laboratory studies to investigate potential frog toxicants and evaluated more than 90 chemical agents (agricultural pesticides and pharmaceutical and household products) and 170 chemical formulations (Pitt \& Sin 2004a, Pitt \& Doratt 2006). Only eight of the products were effective as frog toxicants and only three products (caffeine, hydrated lime and citric acid) were at various points in time approved for frog control. From 2001-2002, caffeine was approved for limited use and although it was effective it never was approved for widespread use to due to human health concerns. In 2002, $16 \%$ solution of citric acid, a common food additive, was found to be effective in controlling frog populations with minimal non-target effects (Pitt \& Sin 2004b). Since that time, citric acid has been used by government agencies, nurseries, and homeowners to manage frog populations across the islands and in quarantine areas. Although safe and effective, the primary drawbacks of a citric acid solution are the cost of citric acid ( $\$ 0.26 /$ liter), the need to haul water to mix solutions, and some phytotoxic effects (leaf burn) to certain sensitive plants. Hydrated lime was effective $(3-6 \%$ solutions) as a toxicant and popular to use because it was inexpensive ( $\$ 0.02 /$ liter $)$. In Hawaii, hydrated lime was legal for use from 2005 to 2008, but widespread misuse of powdered lime and caustic effects of the product resulted in the label not being renewed. In response to the loss of the hydrated lime label, potassium and sodium bicarbonate were evaluated as solutions and as powders. Potassium bicarbonate was effective as a dust at an application rate equivalent to $111 \mathrm{~kg} / \mathrm{ha}$ of product or above $12 \%$ as a solution. Sodium bicarbonate was effective as a dust at an application rate equivalent to 444 $\mathrm{kg} / \mathrm{ha}$ of product or above $25 \%$ as a solution. Although effective and few non-target effects, neither product was registered for use. Currently, citric acid is the only approved chemical for controlling coqui frogs in Hawaii.

\section{Conclusion}

Currently, coqui frogs are widespread on the Island of Hawaii with over 50,000 ha infested and few large scale efforts have been taken to manage frogs in the past few years. However, eradication efforts have been successful on the other islands and current quarantine measures have reduced the number of new populations arising. On Oahu, a large naturalised population has been eradicated using citric acid spraying and other small or incipient populations have also been removed, therefore Oahu has no frog populations. On Kauai, most populations have been removed with citric acid spraying and a larger population ( 6 ha) has been greatly reduced using a combination of citric acid spraying and vegetation removal. On Maui, seven populations have been removed and six others have been greatly reduced with citric acid spraying. One large population remains on Maui in Maliko Gulch, because steep terrain has restricted ground based citric acid spraying. However, a new effort has commenced that includes a several other methods to dispense citric acid including high volume sprayer, helicopter with fire fighting buckets, and trailer mounted spray systems.

Overall, control of invasive species is difficult once the species is established or widespread. Once coqui frogs were initially established on the Island of Hawaii and Maui, little effort went into controlling their spread, eradicating the populations, or studying the problem despite warnings about the potential impacts (Kraus \& Campbell 1999). As is typical for many species introductions, once coqui frogs were widespread, public calls for their control were initiated and funding was available for control but the probability of success declined rapidly. The effort was not able to eradicate frogs from the Island of Hawaii because they were widespread and firmly established, but fortunately further spread was slowed and frogs were eradicated from other islands. Obviously, to stem the tide of invasive species efforts must be directed toward reducing the introduction of new species, research on methods development, and managing species before they are widespread.

\section{References}

Beard, K. H. 2007. Diet of the invasive frog, Eleutherodactylus coqui, in Hawaii. Copeia. 2007:281-291.

Beard, K. H., R. Al-Chokhachy, N. C. Tuttle, \& E. M. O’Neill. 2008. Population density and growth rates of Eleutherodactylus coqui in Hawaii. J. Herpetol. 42:626-636.

Beard, K. H. \& O'Neill, E. M. 2005. Infection of an invasive frog Eleutherodactylus coqui by the chytrid fungus Batrachochytrium dendrobatidis in Hawaii', Biological Conservation. 126:591595.

Beard, K. H., E. A. Price, \& W. C. Pitt. 2009. Biology and impacts of Pacific Island invasive species: Eleutherodactylus coqui, the Coqui frog (Anura: Leptodactylidae). Pacific Science. 63(3):297316.

Beard, K. H., \& W. C. Pitt. 2005. Potential consequences of the coqui frog invasion in Hawaii. Divers. Distrib. 11:427-433.

Beard, K. H., \& W. C. Pitt. 2006. Potential predators of an invasive frog Eleutherodactylus coqui in Hawaii rain forests. Journal of Tropical Ecology. 22:345-347.

Choi, R. T, \& K. H. Beard. 2012. Coqui frog invasions change invertebrate communities in Hawaii. Biological Invasions 14: 938-948.

Hara, A. H., Jacobsen, C. M., Marr, S. R. \& Niino-DuPonte, R. Y. 2010. 'Hot water as a potential disinfestation treatment for an invasive anuran amphibian, the coqui frog, Eleutherodactylus coqui Thomas (Leptodactylidae), on potted plants', International Journal of Pest Management. 56:255-263

Kaiser, B., \& K. Burnett. 2006. Economic impacts of E. coqui frogs in Hawaii. Interdisciplinary Environmental Review. 8:1-11.

Kraus, F., E. W. Campbell, A. Allison, \& T. Pratt. 1999. Eleutherodactylus frog introductions in Hawaii. Herp.Rev. 30:21-25.

Kraus, F., \& E. W. Campbell. 2002. Human-mediated escalation of a formerly eradicable problem: the invasion of Caribbean frogs in the Hawaiian Islands. Biological Invasion. 4:327-332.

Marr, S. R., W. J. Mautz, \& A. H. Hara. 2008. Parasite loss and introduced species: A comparison of the parasites of the Puerto Rican tree frog, (Eleutherodactylus coqui), in its native and introduced ranges. Biological Invasion. 10:12891298. 
Pitt, W. C., \& R. E. Doratt. 2006. Screening for the evaluation of selected chemicals and pesticides to control Eleutherodactylus frogs in Hawaii. Rep. No.QA-1208.USDA/APHIS/WS/NWRC, Hilo, Hawaii, USA.

Pitt, W. C., \& R. E. Doratt. 2008. Dermal toxicity of sodium bicarbonate to control Eleutherodactylus frogs in Hawaii. USDA, APHIS, WS, NWRC. Hilo, Hawaii, USA.

Pitt, W. C., \& H. Sin. 2004a. Dermal toxicity of citric acid based pesticides to introduced Eleutherodactylus frogs in Hawaii. QA-992 Final Report USDA, APHIS,WS,NWRC, Hilo, Hawaii, USA $11 \mathrm{pp}$.

Pitt, W. C., \& H. Sin. 2004b. Field efficacy and invertebrate nontarget hazard assessment of citric acid spray application for control of introduced Eleutherodactylus frogs in Hawaii. QA-1048 Final Report.USDA/APHIS/WS/NWRC, Hilo, Hawaii, USA 12 pp.

Sin, H., K. H. Beard, \& W. C. Pitt. 2008. An invasive frog, Eleutherodactylus coqui, has top-down effects on new leaf production and leaf litter decomposition rates through nutrient cycling in Hawaii. Biol. Invasions. 10:335-345.

Sugihara, R. T. 2000. Coqui trap study summary. USDA/APHIS/WS/ NWRC, Hilo, Hawaii, USA 2 pp.

William Pitt is the field station leader for USDA APHIS Wildlife Services National Wildlife Research Center's Hawaii Field Station and he directs a diverse research project on invasive species across the Pacific Basin. His current research focuses on reducing the effects of rodents, mongoose, brown treesnakes, and tree frogs on natural resources, economics, and human health and safety.

William Pitt is the field station leader for USDA APHIS Wildlife Services National Wildlife Research Center's Hawaii Field Station and he directs a diverse research project on invasive species across the Pacific Basin. His current research focuses on reducing the effects of rodents, mongoose, brown tree snakes, and tree frogs on natural resources, economics, and human health and safety

Karen Beard is an Associate Professor in the Department ofWildland Resources and the Ecology Center at Utah State University. She specializes in conservation biology and particularly on the study of invasive species from introduction through management. She has been studying coqui frogs in their native and introduced ranges for 15 years.

Rogelio Doratt was born in El Salvador, is married and has two children. He received degrees from Humboldt State University and University of Hawaii at Hilo. Currently, he works for Colorado State University, Center for Environmental Management of Military Lands at Pohakuloa Training Area, Natural Resource Office, Hawaii as the Wildlife Program Manager.

\section{Future articles in Outlooks on Pest Management will include -}

- Pest status of the brown marmorated stink bug,

Halyomorpha halys, in the USA

- Potential Exposure to pesticides based on actual residue levels

- The Farm4Bio consortium

- The use of pesticides in houses

- Pesticide emission models

- The work of IRAC

- Estimating human risk resulting from exposure to pesticides

- Sudden Oak Death in the UK

- Neonicotinic resistance

- The development of insect repellents

- An emerging mouse plague developing in southern Australia

- Collection of pesticide containers

- The molecular basis of resistance to SDHI fungicides

- The benefits of plant breeding

- IP and saved seed in Europe

Why are there not more GM crops?

- The Waste Directive

- Banana diseases
- Non-target or secondary effects of fungicides

- Fungicide resistance in Brazil

- Insecticide discovery in the post-genomic era

- The SCARDA programme and its impact on African agriculture

- Opportunities for non-food crops in today's farming systems

- Controlling potato cyst nematode in potato crops with a fungus

- Pesticide container disposal from US and International perspectives

- Counterfeiting and other illegal PPPs

- The abuse of the parallel trade rules for the supply and distribution of illegal/unregistered PPPs across Europe

- Insecticide Toxicology with particular reference to cotton ecosystems

- The changing face of farm economics in Europe

- Opportunities and Initiatives to minimise children's exposures to pesticides

- Economics of insect pathogens used for insect management 